\title{
Relationship between performance status and satisfaction with fentanyl pectin nasal spray
}

\author{
L.M. Torres ${ }^{1}$, D.M. Thorpe ${ }^{2}$, A.D. Knight ${ }^{3}$ and M. Perelman ${ }^{4}$ \\ ${ }^{1}$ Hospital Universitario Puerta del Mar. Cádiz, Spain. ${ }^{2}$ Huntsman Cancer Institute. Salt Lake City, UT. USA. \\ ${ }^{3}$ Evicom Ltd. Teddington, UK. ${ }^{4}$ Archimedes Development Ltd. Nottingham, UK
}

Torres LM, Thorpe DM, Knight AD, Perelman M. Relationship between performance status and satiffaction with fentanyl pectin nasal spray. Rev Soc Esp Dolor 2014; 21(4): 191-196.

\begin{abstract}
Background: Patients with breakthrough pain in cancer (BTPc) experience impaired activities of daily living and quality of life. Both function and satisfaction with treatment can impact patients' abilities to use products, and likely impact response to therapies.

Objective: This exploratory analysis examined the relationship between functional status and satisfaction with ability to use fentanyl pectin nasal spray (FPNS) for BTPc.

Methods: Treatment satisfaction data were analyzed from a multicenter, open-label, long-term study using FPNS for managing BTPc in patients with Eastern Cooperative Oncology Group (ECOG) grade $\leq 2$. Satisfaction with ease of use, convenience, and reliability of FPNS were assessed on three-question, fourpoint scales ( 1 = not satisfied, 2 = not satisfied or dissatisfied, 3 = satisfied, 4 = very satisfied) at the end of $1,4,8$, and 12 weeks. For each domain, percentage of patients who reported being "satisfied or very satisfied" (score 3 or 4) with FPNS was analyzed based on ECOG grade.

Results: Overall, > $90 \%$ of patients with ECOG 0-2 reported being satisfied or very satisfied with FPNS across all three domains. Differences in patient satisfaction with FPNS by ECOG grade were clinically small though statistically significant (ease of use: $p=$ 0.0022, convenience: $p=0.0057$, and reliability: $p=0.0012$ ).

Conclusion: The FPNS device was well accepted irrespective of ECOG grade (0-2). Statistically, patients with higher performance status (lower ECOG grades) reported higher sat-
\end{abstract}

Received: 02-03-13.

Accepted: 04-06-13. isfaction scores, though effect size was small. Results imply the FPNS device provides a high level of usability irrespective of functional status, which is likely to promote use and thus likelihood of success in controlling BTPC.

Key words: Breakthrough pain. Cancer. Fentanyl pectin nasal spray. Function. Transmucosal fentanyl. Treatment satisfaction.

\section{RESUMEN}

Introducción: los pacientes con dolor irruptivo oncológico (BTPc) experimentan un deterioro de las actividades de la vida diaria y de la calidad de vida. Tanto la función como la satisfacción con el tratamiento pueden afectar a las capacidades de los pacientes para utilizar fármacos e impactar en sus respuestas a los mismos.

Objetivo: este análisis exploratorio examina la relación entre el estado funcional y la satisfacción con la capacidad de usar el aerosol nasal de pectina de fentanilo (FPNS) para BTPc.

Métodos: se analizaron datos de satisfacción del tratamiento de un estudio multicéntrico, abierto, a largo plazo usando FPNS para el tratamiento del BTPc en pacientes con Eastern Cooperative Oncology Group (ECOG) grado $\leq 2$. Fueron evaluados

\footnotetext{
Funding: Medical writing and editorial assistance were supported by Archimedes Development Ltd.

Conflict of interest disclosures: Luis M. Torres is a consultant for Ferrer and ProStrakan, and is on the speakers' bureaus of Cephalon and Archimedes Development Ltd. Deborah M. Thorpe has been a consultant for Archimedes Nurse Advisory Board; is on the speakers' bureau of Pfizer Inc; has received grant/research support from Archimedes Development Ltd; and holds stock in Abbott Laboratories. Michael Perelman is employed by Archimedes Development Ltd. Alastair D. Knight serves as a statistical consultant to Archimedes Development Ltd. This manuscript contains information originally presented at the 2012 Multinational Association of Supportive Care in Cancer (MASCC)/International Society of Oral Oncology (ISOO) International Symposium on Supportive Care in Cancer held in New York, NY, on June 28-30, 2012.
} 
la satisfacción con la facilidad de uso, comodidad y fiabilidad de FPNS en escalas tres preguntas y cuatro puntos ( 1 = nada satisfecho, 2 = no satisfecho o insatisfecho, 3 = satisfecho, $4=$ muy satisfecho) al final de 1, 4, 8 y 12 semanas. Para cada dominio, el porcentaje de pacientes que informaron estar "satisfechos o muy satisfechos" (puntuación de 3 o 4) con FPNS se analizó basado en el grado ECOG.

Resultados: en general, el $90 \%$ de los pacientes con ECOG 0-2 dijo haber estado satisfecho o muy satisfecho con la FPNS en los tres dominios. Diferencias en la satisfacción del paciente con FPNS por grado ECOG fueron clínicamente pequeñas pero estadísticamente significativas (facilidad de uso: $p=0,0022$, conveniencia: $p=0,0057$ y fiabilidad: $p=0,0012$ ).

Conclusión: el dispositivo FPNS fue bien aceptado independientemente del grado ECOG (0-2). Estadísticamente, los pacientes con status de rendimiento superior (grados menores ECOG) informaron mayores puntuaciones de satisfacción, aunque el tamaño del efecto fue pequeño. Los resultados demuestran que el dispositivo FPNS proporciona un alto nivel de usabilidad independientemente del estado funcional, y que es probable que promover el uso y por lo tanto la probabilidad de éxito en el control de BTPc.

Palabras clave: Dolor irruptivo. Cáncer. Aerosol nasal de fentanilo pectina. Función. Fentanilo transmucosa. Satisfacción con el tratamiento.

\section{BACKGROUND}

The majority of patients with cancer suffer pain, and most of those patients experience breakthrough pain (BTPc) (Caraceni et al., 1999; Caraceni et al., 2012a; Gatti et al., 2012), an acute exacerbation of pain despite relatively stable and adequately controlled background pain (Davies et al., 2009). The clinical characteristics of BTPc vary, but typically patients report a rapid onset of pain (median interval of 3-15 min to peak), moderate duration (median, 30-60 min), and high severity (Portenoy et al., 1990; Portenoy et al., 1999; Portenoy et al., 2010a; Davies et al., 2011a).

BTPc can occur spontaneously, or in relation to a specific trigger. Activities such as movement can precipitate BTPc (Portenoy et al., 1999). Patients who have higher function may be more active and consequently may be more prone to having episodes of BTPc. Conversely, BTPc can impact a patient's ability to perform normal daily activities, and unrelieved BTPc can be debilitating (Abernethy et al., 2008). Among patients with controlled background cancer pain, those who have BTPc had more functional impairment than those without BTPc (Portenoy et al., 1999). This was reflected in significantly more impairment of activity levels, social relations, work, sleep, and enjoyment of life, as well as significantly greater psychological distress including depression and anxiety in the group of patients with BTPc (Portenoy et al., 1999).
Patient function, satisfaction, and quality of life are therefore interrelated: BTPc can have a detrimental impact on function that can contribute to an impaired quality of life, while successful treatment of BTPc has the potential to improve quality of life. Satisfaction with use of a treatment can lead to greater adherence (Radbruch et al., 2012) and, consequently, a greater chance for a successful outcome.

Fentanyl pectin nasal spray (FPNS; Lazanda ${ }^{\circledR}$ in the United States, PecFent ${ }^{\circledR}$ in Europe and Australia) is a novel presentation of fentanyl. Because the nasal route is not particularly common, its unfamiliarity to patients may impact its usability and acceptance. A 2003 survey that included 100 patients with BTPc reported that only $16 \%$ of patients had prior experience with a nasal route of administration for analgesic medication (Walker et al., 2003). Results of the study suggested that patient acceptability of the intranasal route of administration could be adversely impacted by unfamiliarity and questions about administration.

Usability may be further affected by functional status, with lower functioning individuals feeling reluctant to use a new treatment modality. To assess this possibility, we performed a post hoc analysis of data from a multicenter, open-label, long-term study of FPNS. This analysis examined the relationship between functional status (as measured by Eastern Cooperative Oncology Group [ECOG] performance status) (Oken et al., 1982) and satisfaction with the use of FPNS.

\section{METHODS}

Data were extracted from an international long-term use study conducted in 91 centers located across the United States, Europe, India, and South America, the details of which have been described previously (Portenoy et al., 2010c). The study was conducted in accordance with the International Conference on Harmonisation recommendations for Good Clinical Practice and the Declaration of Helsinki and approved by the institutional review boards of each site. All patients provided informed consent prior to inclusion in the study.

Patients were aged $\geq 18$ years and had any type of cancer accompanied by related, persistent pain adequately controlled by $\geq 60 \mathrm{mg} /$ day oral morphine (or equivalent) (Portenoy et al., 2010c). The patients included in this study had either been part of a previous double-blind trial of efficacy and safety of FPNS (Portenoy et al., 2010b; Davies et al., 2011b) or were newly recruited into this study (Portenoy et al., 2010c) (Fig. 1). All patients experienced an average of one to four daily episodes of moderate-to-severe BTPc and had an ECOG grade $\leq 2$ (Table I) (Oken et al., 1982). ECOG performance status was recorded by investigators during screening in the 
prior trial, or for new patients, at entry to this study. All patients entered an initial Titration Phase during which FPNS was titrated to an effective and tolerable dose. Once an optimal dose was identified, patients then entered a Maintenance Phase during which the dose of FPNS was held constant.

Patients recorded satisfaction in an electronic diary using a well-accepted four-point scale: 1 = not satisfied, 2 = not satisfied or dissatisfied, $3=$ satisfied and $4=$ very satisfied at the end of $1,4,8$, and 12 weeks of treatment by answering the three questions (Radbruch et al., 2012):

- How satisfied are you overall with the ease of use of the nasal spray?

- How satisfied are you overall with the convenience of the nasal spray?

- How satisfied are you overall with the reliability of the nasal spray?

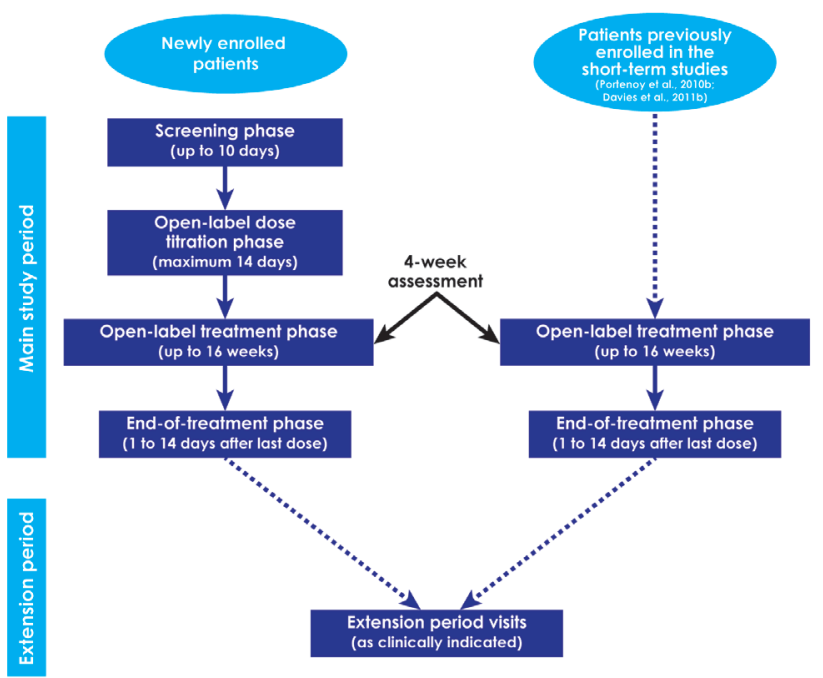

Fig. 1. Study design.
The relationship between functional status (ECOG performance status) at study entry and satisfaction was analyzed using a repeated-measures mixed analysis of variance (ANOVA) model with patients reporting being either "satisfied" or "very satisfied" with the usability of the FPNS device. Patients included in the post hoc analysis were those within the intent-to-treat (ITT) population (i.e. received $\geq 1$ dose of FPNS) who had provided an ECOG performance status score at study entry and supplied satisfaction scores at 4 weeks of FPNS treatment.

\section{RESULTS}

There were 195 patients who provided ECOG performance status scores at study entry and completed assessments of satisfaction at 4 weeks of treatment. Of these, $59.0 \%$ were men, and the mean (SD) age was 53.1 (12.3) years.

Overall, patient satisfaction with the functionality of FPNS across the three domains was high. Statistically, there was a relationship between ECOG grade and satisfaction across all three domains at 4 weeks, although the effect size was small. Analyses of the relationship between patient satisfaction with FPNS and performance status at 8 and 12 weeks revealed no difference to that observed at 4 weeks.

\section{Ease of use}

Overall, at 4 weeks of treatment, $97.4 \%$ of the patients $(n=195)$ in this analysis reported being satisfied or very satisfied with the ease of use of FPNS. Subpopulation analysis, however, did show that more patients with a higher performance status were satisfied or very satisfied with treatment using FPNS than patients with lower status (Fig. 2). Among the 20 patients with an ECOG grade of 0

TABLE I. EASTERN COOPERATIVE ONCOLOGY GROUP (ECOG) GRADES AND PERFORMANCE STATUS (OKEN ET AL., 1982)

\begin{tabular}{cl}
\hline Grade & \multicolumn{1}{c}{ Performance status } \\
\hline 0 & Fully active, able to carry on all pre-disease performance without restriction \\
1 & $\begin{array}{l}\text { Restricted in physically strenuous activity but ambulatory and able to carry out work of a light or } \\
\text { sedentary nature, e.g. light house work, office work }\end{array}$ \\
2 & $\begin{array}{l}\text { Ambulatory and capable of all self-care but unable to carry out any work activities. Up and about more } \\
\text { than } 50 \% \text { of waking hours }\end{array}$ \\
3 & $\begin{array}{l}\text { Capable of only limited self-care, confined to bed or chair more than } 50 \% \text { of waking hours } \\
4\end{array}$ \\
& Completely disabled \\
\end{tabular}


at study entry, $100 \%$ were either satisfied or very satisfied with the ease of use of FPNS at 4 weeks, compared with $97.7 \%$ who had an ECOG grade of $1(n=130)$ and $95.6 \%$ who had an ECOG grade of $2(n=45)$. Indeed, a statistically significant relationship was observed between performance status and the level of patient satisfaction across the time period of the study for the ease of use of FPNS $(p=0.0022)$.

\section{Convenience}

Similarly, $96.9 \%$ of the patients in this analysis were satisfied or very satisfied with the convenience of FPNS, and a subpopulation analysis showed a further relationship between performance status at the start of the study and satisfaction with convenience of FPNS. At 4 weeks of treatment, $100 \%$ of those with an ECOG grade of 0 at study entry were either satisfied or very satisfied with the convenience of FPNS, compared with $96.9 \%$ of those with an ECOG grade of 1, and $95.6 \%$ who had an ECOG grade of 2 . In addition, satisfaction with convenience was statistically significantly correlated to ECOG performance status across the study period $(p=0.0057)$.

\section{Reliability}

Among all patients regardless of performance status, $92.3 \%$ were satisfied or very satisfied with the reliability of FPNS. But once again, more patients with higher performance status (100\% with an ECOG 0) reported being satisfied or very satisfied with the reliability of FPNS than those with lower statuses: $92.3 \%$ with an ECOG grade of 1 and $88.9 \%$ with an ECOG grade of 2 . A statistically significant relationship was observed between ECOG performance status and the level of patient satisfaction across the time period of the study for the reliability $(p=0.0012)$ of FPNS.

\section{DISCUSSION}

BTPc is a distinct component of cancer pain that is known to decrease function and quality of life (Portenoy et al., 2010d). Given the rapid onset, moderate duration and high severity of pain, treatments that provide rapid onset of action, with a limited duration of effect, are a needed addition to the available pharmacologic options (Zepetella et al., 2006). Recent guidelines support the use of transmucosal fentanyl formulations for management of BTPc (Caraceni et al., 2012b; National Comprehensive Cancer Network, 2012).

Patient satisfaction with use of a treatment is important to establish as it can affect treatment adherence, which
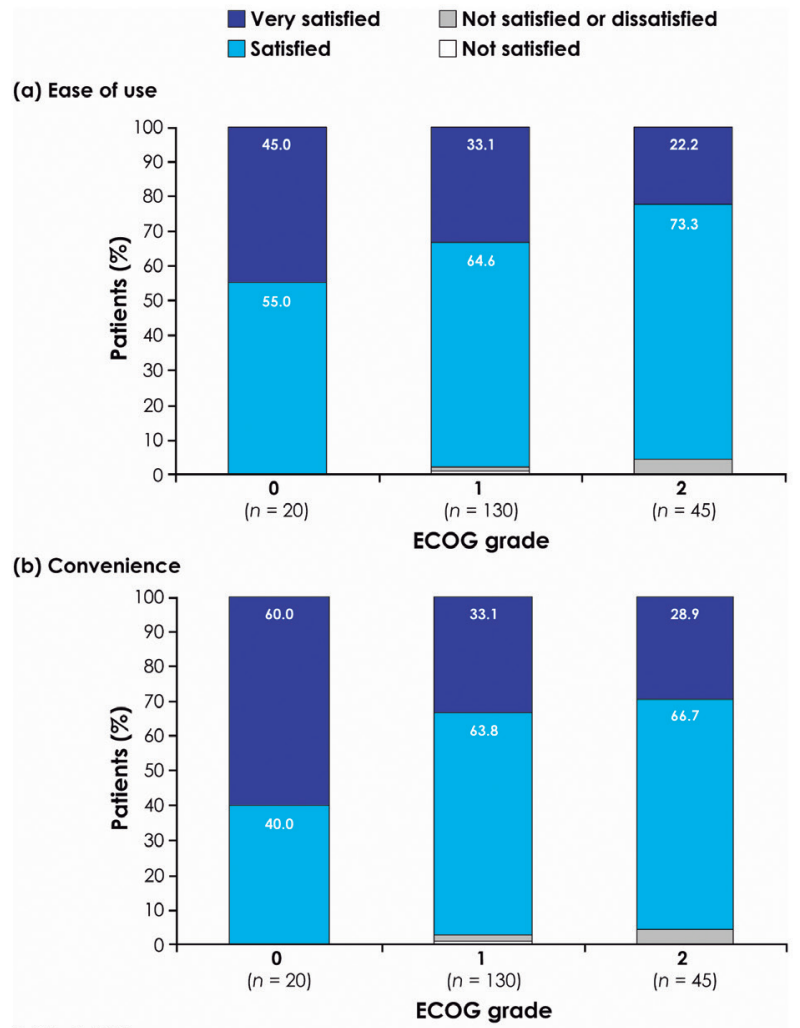

(c) Reliability

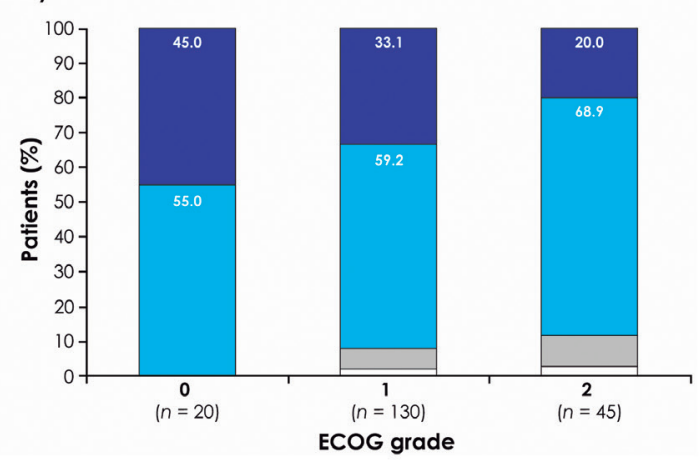

Fig. 2. Patient satisfaction with FPNS at 4 weeks with ease of use (a), convenience (b), and reliability (c). ECOG Grade, Eastern Cooperative Oncology Group; FPNS, fentanyl pectin nasal spray.

can be challenging especially in the management of BTPc (Radbruch et al., 2012). Many patients do not take rescue medication every time they have an episode of BTPc (Davies et al., 2008) and the majority of patients who have BTPc take lower doses of rescue medication than prescribed (Ferrell et al., 1999; Miaskowski et al., 2001). Patients who find their treatment easy to use, convenient, and reliable might be more likely to adhere to their treatment plan and thus gain analgesic benefit. The high level of acceptance reported in these patients across three domains in the current analysis may be important for patient com- 
pliance and successful management of BTPc. Results of a long-term study, in which patients continued to use FPNS for management of BTPc for as long as 3 years, suggest that FPNS is safe and effective for long-term use (Taylor et al., 2013).

Once the nature of BTPc is diagnosed, tailoring a treatment to the needs of a patient will likely lead to better acceptability and thus provide a better response to treatment.

FPNS has been formulated for consistent absorption across the nasal mucosa with minimal runoff or swallowing to provide rapid relief of BTPc (Portenoy et al., 2010c). While a previous survey suggested that few patients had prior experience with a nasal route of analgesic medication (Walker et al., 2003), two recent randomized controlled studies of FPNS found that $69-80 \%$ of patients were satisfied or very satisfied with the ease of use and convenience (Portenoy et al., 2010b; Davies et al., 2011b). It should be noted, however, that many of the patients in this "extension study" were pre-selected because of a successful response in the preceding double-blind trials.

In this secondary analysis, more than $90 \%$ of patients were satisfied or very satisfied with their treatment using FPNS and the device itself. This finding was evident after 4,8 , and 12 weeks of treatment suggesting that any learning effect related to device use occurred early and was sustained. This exploratory analysis is the first to examine a potential relationship between functional status and the level of patient satisfaction attained with the use of a treatment for BTPc. While more than $90 \%$ of patients with ECOG grades ranging from $0-2$ were satisfied or very satisfied with use of FPNS, those patients with a higher performance status had a statistically significant tendency to report better satisfaction with the ease of use than those with lower status, though the difference was clinically small. Similarly, patients with a higher performance status also reported better satisfaction with the convenience and reliability of FPNS than those with a lower status.

Patients with a variety of cancer types participated in the current study and reported high levels of satisfaction with the FPNS formulation across all three domains of functionality. But, it must be recognized that this post hoc analysis is limited by the patient population of the primary studies, which were limited to patients with ECOG grades of 0-2. Patients with ECOG grades $>2$ may have further limitations and greater difficulty in managing BTPc due to functional impairments. It would be useful to explore the relationship between lower functional states and the ability to use products like FPNS in future studies.

\section{CONCLUSIONS}

Overall, more than $90 \%$ of patients with ECOG performance status 0-2 reported a high level of satisfac- tion (across three domains of functionality) with the use of FPNS treatment. While satisfaction was statistically greater in patients with higher performance status, clinical difference was small. This suggests that patients with higher performance status (ECOG 0-2) are able to use FPNS with relative ease and that FPNS represents a useful treatment option for the management of breakthrough pain. Future studies should address the utility of products for BTPc in patients with lower performance status $(\mathrm{ECOG}>2)$.

\section{AUTHOR CONTRIBUTIONS}

A.K. provided statistical analysis. All authors contributed to interpretation of the data, initiated development of and provided comments throughout the manuscript development, and approved the final version to be published.

\section{ACKNOWLEDGMENTS}

Medical writing support and editorial assistance were provided by Rebecca Bachmann, Sharon Suntag, and Julie Gerke of Quintiles.

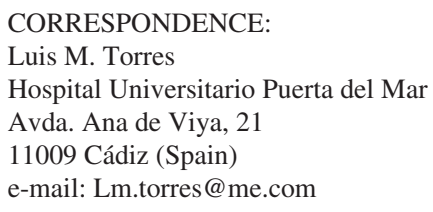

\section{REFERENCES}

1. Abernethy AP, Wheeler JL, Fortner BV. A health economic model of breakthrough pain. Am J Manag Care 2008;14:S129-S140.

2. Caraceni A, Portenoy RK. An international survey of cancer pain characteristics and syndromes. IASP Task Force on Cancer Pain. International Association for the Study of Pain. Pain 1999;82:263-74.

3. Caraceni A, Bertetto O, Labianca R, Maltoni M, Mercadante S, Varrassi G, et al.; Breakthrough/Episodic Pain Italian Study Group. Episodic (breakthrough) pain prevalence in a population of cancer pain patients. Comparison of clinical diagnoses with the QUDEI-Italian questionnaire for intense episodic pain. J Pain Symptom Manage 2012a;43:833-41.

4. Caraceni A, Hanks G, Kaasa S, Bennett MI, Brunelli C, Cherny N, et al.; European Palliative Care Research Collaborative (EPCRC); European Association for Palliative Care (EAPC). Use of opioid analgesics in the treatment of cancer pain: Evidence-based recommendations from the EAPC. Lancet Oncol 2012b;13:e58-e68. 
5. Davies AN, Vriens J, Kennett A, McTaggart M. An observational study of oncology patients' utilization of breakthrough pain medication. J Pain Symptom Manage 2008;35:406-11.

6. Davies AN, Dickman A, Reid C, Stevens AM, Zeppetella G. The management of cancer-related breakthrough pain: Recommendations of a task group of the Science Committee of the Association for Palliative Medicine of Great Britain and Ireland. Eur J Pain 2009;13:331-8.

7. Davies A, Zeppetella G, Andersen S, Damkier A, Vejlgaard T, Nauck F, et al. Multi-centre European study of breakthrough cancer pain: Pain characteristics and patient perceptions of current and potential management strategies. Eur J Pain 2011a;15:756-63.

8. Davies A, Sitte T, Elsner F, Reale C, Espinosa J, Brooks D, et al. Consistency of efficacy, patient acceptability, and nasal tolerability of fentanyl pectin nasal spray compared with immediate-release morphine sulfate in breakthrough cancer pain. J Pain Symptom Manage 2011b;41:358-66.

9. Ferrell BR, Juarez G, Borneman T. Use of routine and breakthrough analgesia in home care. Oncol Nurs Forum 1999;26:1655-61.

10. Gatti A, Mediati RD, Reale C, Cuomo A, Vellucci R, Russo $\mathrm{G}$, et al. Breakthrough pain in patients referred to pain clinics: The Italian pain network retrospective study. Adv Ther 2012;29:464-72.

11. Miaskowski C, Dodd MJ, West C, Paul SM, Tripathy D, Koo $\mathrm{P}$, et al. Lack of adherence with the analgesic regimen: A significant barrier to effective cancer pain management. J Clin Oncol 2001;19:4275-9.

12. National Comprehensive Cancer Network. NCCN Clinical Practice Guidelines in Oncology: Adult Cancer Pain, Version 1.2012.

13. Oken MM, Creech RH, Tormey DC, Horton J, Davis TE, McFadden ET, et al. Toxicity and response criteria of the Eastern Cooperative Oncology Group. Am J Clin Oncol 1982;5:649-55.
14. Portenoy RK, Hagen NA. Breakthrough pain: Definition, prevalence and characteristics. Pain 1990;41:273-81.

15. Portenoy RK, Payne D, Jacobsen P. Breakthrough pain: Characteristics and impact in patients with cancer pain. Pain 1999;81:129-34.

16. Portenoy RK, Bruns D, Shoemaker B, Shoemaker SA. Breakthrough pain in community-dwelling patients with cancer pain and noncancer pain, part 1: Prevalence and characteristics. J Opioid Manag 2010a;6:97-108.

17. Portenoy RK, Burton AW, Gabrail N, Taylor D. A multicenter, placebo-controlled, double-blind, multiple-crossover study of Fentanyl Pectin Nasal Spray (FPNS) in the treatment of breakthrough cancer pain. Pain 2010b;151:617-24.

18. Portenoy RK, Raffaeli W, Torres LM, Sitte T, Deka AC, Herrera IG, et al.; Fentanyl Nasal Spray Study 045 Investigators Group. Long-term safety, tolerability, and consistency of effect of fentanyl pectin nasal spray for breakthrough cancer pain in opioid-tolerant patients. J Opioid Manag 2010c;6:319-28.

19. Portenoy RK, Bruns D, Shoemaker B, Shoemaker SA. Breakthrough pain in community-dwelling patients with cancer pain and noncancer pain, part 2: Impact on function, mood, and quality of life. J Opioid Manag 2010d;6:109-16.

20. Radbruch L, Torres LM, Ellershaw JE, Gatti A, Luis Lerzo G, Revnic J, et al. Long-term tolerability, efficacy and acceptability of fentanyl pectin nasal spray for breakthrough cancer pain. Support Care Cancer 2012;20:565-73.

21. Taylor D, Radbruch L, Revnic J, Torres LM, Ellershaw JE, Perelman M. A report on the long-term use of fentanyl pectin nasal spray in cancer patients with recurrent breakthrough pain. J Pain Symptom Manage 2013 [Epub ahead of print].

22. Walker G, Wilcock A, Manderson C, Weller R, Crosby V. The acceptability of different routes of administration of analgesia for breakthrough pain. Palliat Med 2003;17:219-21.

23. Zeppetella G, Ribeiro MD. Opioids for the management of breakthrough (episodic) pain in cancer patients. Cochrane Database Syst Rev 2006;CD004311. 